\title{
An experimental investigation for pullout response of a single granular pile anchor in clayey soil
}

\author{
Hans Raj Vashishtha and Vishwas A. Sawant ${ }^{*}$ (D)
}

*Correspondence:

vishwas.sawant@ce.iitr.ac.in Department of Civil

Engineering, Indian Institute of Technology Roorkee,

Roorkee 247667, India

\begin{abstract}
The granular pile anchor foundation is an effective and economical foundation system to counter the pullout forces exerted in case of transmission towers or foundations in expansive soil. The pullout tests were performed to study the behaviour of a single granular pile anchor in the clayey soil bed. Tests were conducted in a steel tank of 1 $\times 1 \times 1 \mathrm{~m}$ size with the help of loading frame arrangement. The pullout load required for upward movement equal to $10 \%$ diameter was considered as the pullout capacity of the granular pile anchor. In the parametric study, length and diameter of the granular pile anchor were varied to examine their effect. Number of anchor plates was also varied in few tests. The pullout capacity enhanced with an increase in the diameter and length to diameter ratio. The effect of the length to diameter ratio was appreciable up to the value of 10. However, no significant effect was found in the cases of multiple anchor plates. A relationship is proposed to predict normalized pullout capacity.
\end{abstract}

Keywords: Clayey soil bed, Granular pile anchor, Upward movement, Pullout loads, Pullout capacity, Normalized pullout capacity

\section{Introduction}

Concurrent with the development of communication networks during the recent years, many mobile communication towers have embarked at various places. These transmission towers are subjected to significant wind loads. It generates uplift forces on the foundations on one side and compression on the other side. Similarly foundations in expansive soil also subjected to uplift forces due to swelling behaviour of soil. There are different foundation systems in practice that are capable to combat pullout forces such as bored piles, augured piles, cast in situ bored concrete piles, under-reamed piles, driven H-piles, and granular pile anchors. The granular pile anchor (GPA) foundation system is an effective and economical foundation system to resist the pullout forces. In the GPA foundation system, the foundation is axially anchored at the bottom of the granular pile to an anchor plate through anchor rod. A mild steel plate of same diameter as granular pile is devised as anchor plate. This anchoring arrangement through anchor plate and anchor rod enables the GPA to offer resistance towards the pullout forces. The author(s) and the source, provide a link to the Creative Commons licence, and indicate if changes were made. The images or other third party material in this article are included in the article's Creative Commons licence, unless indicated otherwise in a credit line to the material. If material is not included in the article's Creative Commons licence and your intended use is not permitted by statutory regulation or exceeds the permitted use, you will need to obtain permission directly from the copyright holder. To view a copy of this licence, visit http:// creativecommons.org/licenses/by/4.0/. 
lateral swelling pressure in the surrounding cohesive soil confines the GPA radially and develops resistance against pullout.

Figure 1 shows the concept of a GPA and different forces working on it. A GPA foundation system is designed by considering pullout force on the foundation $\left(P_{u}\right)$ and the sum of all the resisting forces $\left(P_{R}\right)$. The pullout force $\left(P_{u}\right)$ is caused by tensile forces coming to the foundations in cohesionless soils. In the case of expansive soils, pullout force is caused by the swelling pressure $\left(p_{s}\right)$. The pullout resistance $\left(P_{R}\right)$ is developed from self-weight $\left(W_{g p a}\right)$ of the GPA, and the shear resistance mobilized over the entire length of the cylindrical pile-soil interface.

Two failure modes are observed in case of GPA depending upon the length. Shaft failure is observed in case of short GPAs, whereas end bulging failure is noticed in long GPA. In shaft failure, the ultimate pullout capacity is the sum of the mobilized shear resistance around the shaft area and the self-weight of the gravel column. Compression of the stone column under vertical loads and dilation of the dense gravel lead to considerable relative movement between the GPA and surrounding soil. This results in the increase in the normal stresses on the soil-GPA interface. Under such conditions, gravel particles can move into the surrounding soil mass. At ultimate pullout capacity, the failure surface develops within the soil surrounding AGP.

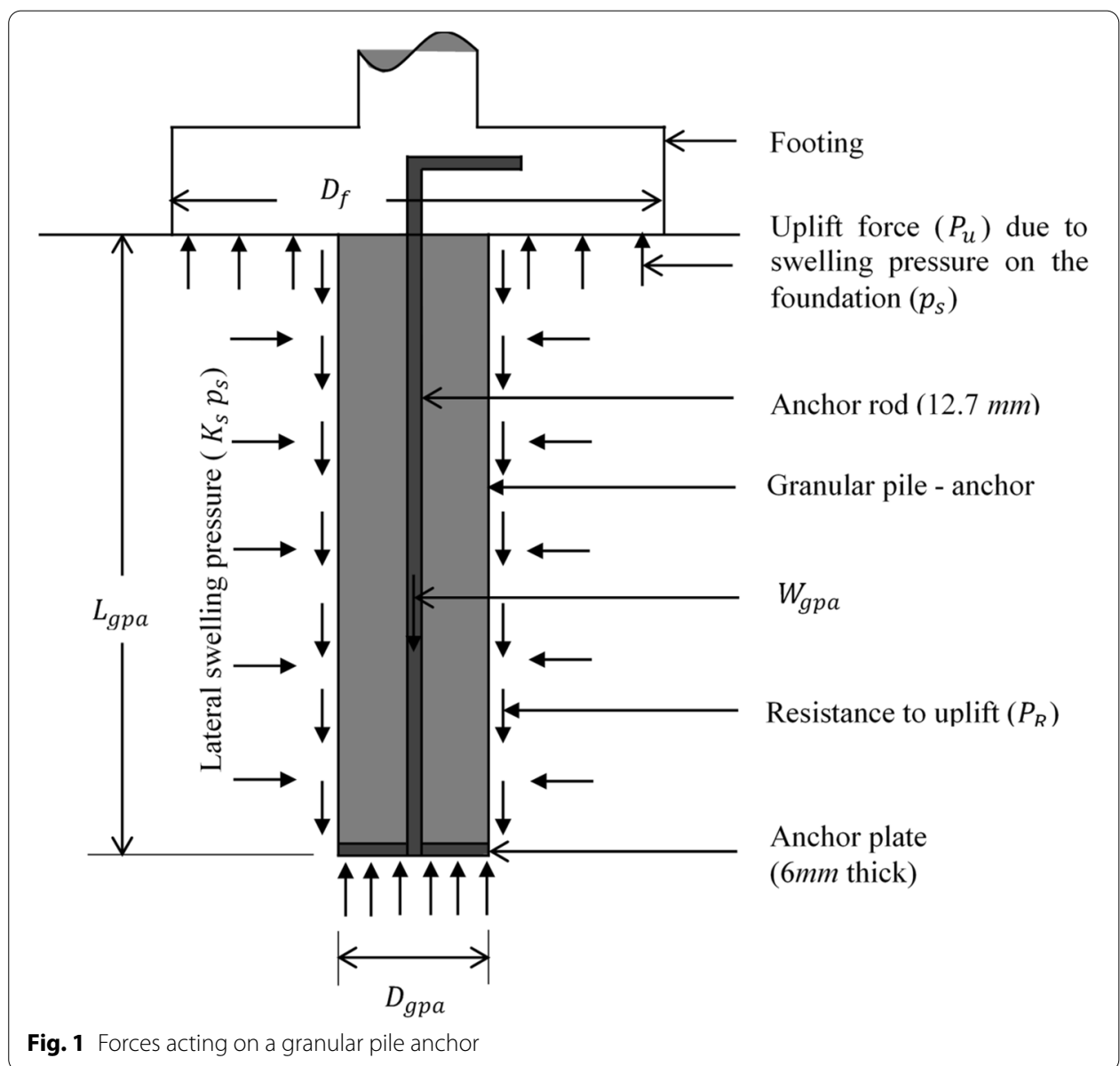


In longer GPAs, initially the uplift force is balanced by shaft resistance mobilized in the lower section of the AGP. With the increase in uplift force, the relative movements between the column and surrounding soil increases. The shaft resistance initiates from the column base and progress upwards along the column length. With further increments, shaft resistance is mobilized over an increasing distance from the column base. Loading can be continued up to a point when failure of the stone column occurs by localized end bulging because of limited lateral confinement in the vicinity of the highly stressed column base. With the buildup in end bulging resistance of the column, the mobilized shaft resistance decreases.

Earlier studies were conducted to examine the pullout behaviour and effect of key parameters as diameter, length to diameter $(L / D)$ ratio using laboratory and numerical investigations. Phanikumar and Rao [1] revealed that the pullout resistance of the GPA was enhanced with the provision of a base geosynthetic. Ranjan and Kumar [2] reported design procedure for the skirted granular pile foundations transmitting sustained vertical and lateral loads in the weak soils. Phanikumar et al. [3] noticed the heave reduction and improvement of the engineering behaviour of expensive clay bed from experimental investigation on the series of GPA. A field-scale test program found that GPAs having larger surface area showed higher pullout capacity [4]. Vidyaranya et al. [5] studied elastoplastic response of the GPAs in a non-homogeneous ground considering the shear stress at the interface to be limited to the undrained strength of the soil. Ismail and Shahin [6] studied the efficacy of a single GPA in a reactive soil bed to arrest both the heave and shrinkage using finite element software PLAXIS3D. Sivakumar et al. [7] presented a new methodology for estimation of the ultimate pullout capacity of the GPA. The dominant mode of failure was observed to be controlled by the $L / D$ ratio and same was verified experimentally. Krishna et al. [8] observed the reduction in the heave of flooring panel by $26 \%, 61 \%$, and $89 \%$ with providing CNS cushion, granular piles, and GPAs, respectively. From the pullout tests conducted in the field, Krishna and Murty [9] reported that the pullout resistance of GPAs was more than twice the value of concrete piles in both unsaturated and saturated states. Ibrahim et al. [10] investigated the performance of GPA in expansive soil focussing in minimizing heave of foundations through experimental and numerical study. An experimental and numerical investigation from O'Kelly et al. [11] found that the undrained pullout capacity of the GPAs was mobilized in shaft capacity or in the end bulging depending on the $L / D$ ratio. Reddy et al. [12] experimentally studied the failure mechanism of the GPAs in clayey sands and silty clays. Study revealed that the failure was possible as shaft failure for $L / D$ less than 7.5 and as bulging failure for $L / D$ greater than 7.5. A criticism of advances related to granular piles/ GPAs was presented encompassing numerical, laboratory, and field investigations of their compressive, pullout, and seismic behaviour [13]. From experimental investigation on the GPA, Johnson and Sandeep [14] observed enhancement in the pullout capacity with an increase in the relative density of granular material. Kranthikumar et al. [15] presented experimental and numerical study on the GPA in loose sandy soil to estimate the ultimate pullout capacity of the GPA. Numerical study was performed using the finite element software PLAXIS3D. The effect of length and stage wise construction was critically checked for the pullout capacity. From experimental investigations, Muthukumar and Shukla [16] found that heave of expansive clay bed was reduced with an increase 
in the number of GPAs, encasing with geosynthetics and an increase in the stiffness of the geosynthetics. Phanikumar [17] reported enhancement in the pullout capacity with increasing layers of geogrid from experimental investigation. Muthukumar and Shukla [18] compared the behaviour of GPAs and helical pile anchors (HPAs) embedded in expansive soil bed from experimental investigations. The heave reduction was more in the case of the GPAs compared to HPAs. Abhishek and Sharma [19] numerically studied the pullout behaviour of GPA embedded in expansive soil bed. Numerical model was developed using finite element software PLAXIS3D. Phanikumar and Muthukumar [20] observed reduction in swelling and shrinkage with an increase in the number of GPAs in a given wetting-drying cycle. Effect was more prominent with an increase in the number of wetting-drying cycles. Sharma and Sharma [21] experimentally investigated the pullout effect of un-reinforced/ reinforced GPAs in un-stabilized/ stabilized soil. Study revealed enhancement in the ultimate pullout load for all the cases with an increase in the length and diameter. Singh et al. [22] studied performance of GPA under oblique pullout loads from experimental investigation. The ultimate pullout loads and efficiency were found to be a function of $L / D$ ratio and angle of inclination of the pullout loads. Phanikumar et al. [23] reported 95\% reduction in the heave of the expansive clay beds on the installation of plain GPAs. It was reduced further with encasement of GPAS with geogrid. Phanikumar and Etukuri [24] observed considerable increase in the CBR value of granular pile reinforced clay samples which improved further with geotextitle encasement of granular pile.

A critical review of the literature pointed out limited attempts towards experimental study on the pullout behaviour of GPA in clayey soils. Few experimental studies are available for GPAs embedded in expansive clayey soils. The impact of providing multiple anchor plates, have not been explored yet. In the present study, an attempt has been made to study the effect of diameter, $L / D$ ratio and multiple anchor plates on the pullout capacity of a single GPA embedded in clayey soil bed.

\section{Experimental investigation}

A series of pullout tests on single GPA embedded in clayey soil bed was conducted in the laboratory. The diameter of GPA was varied from 50 to $100 \mathrm{~mm}$ and $L / D$ ratio was varied from 5 to 15 . The GPAs with multiple anchor plates (2 and 3) were also tested. The effect of diameter, $L / D$ ratio, and providing multiple anchor plates on the pullout capacity of single GPA in clayey soil bed was studied.

\section{Experimental setup}

A steel tank of $1 \times 1 \times 1 \mathrm{~m}$ size with a loading frame was used for the pullout test. The experimental setup is shown in Fig. 2. The loading frame having $1.18 \mathrm{~m}$ length, $1.18 \mathrm{~m}$ breadth and $1.62 \mathrm{~m}$ height was made with a $40 \times 40 \mathrm{~mm}$ size MS section and braced with the $30 \mathrm{~mm}$ diameter MS rods. A $75 \mathrm{~mm}$ deep and $2.27 \mathrm{~m}$ long loading beam was fixed on the top of the loading frame along the length. Three pulleys having $130 \mathrm{~mm}$ diameter were mounted with the loading beam, and these pulleys supported a flexible cable. The one end of the cable was attached to GPA and another end to a circular loading pad of $160 \mathrm{~mm}$ diameter. The foot bases of the loading frame were 


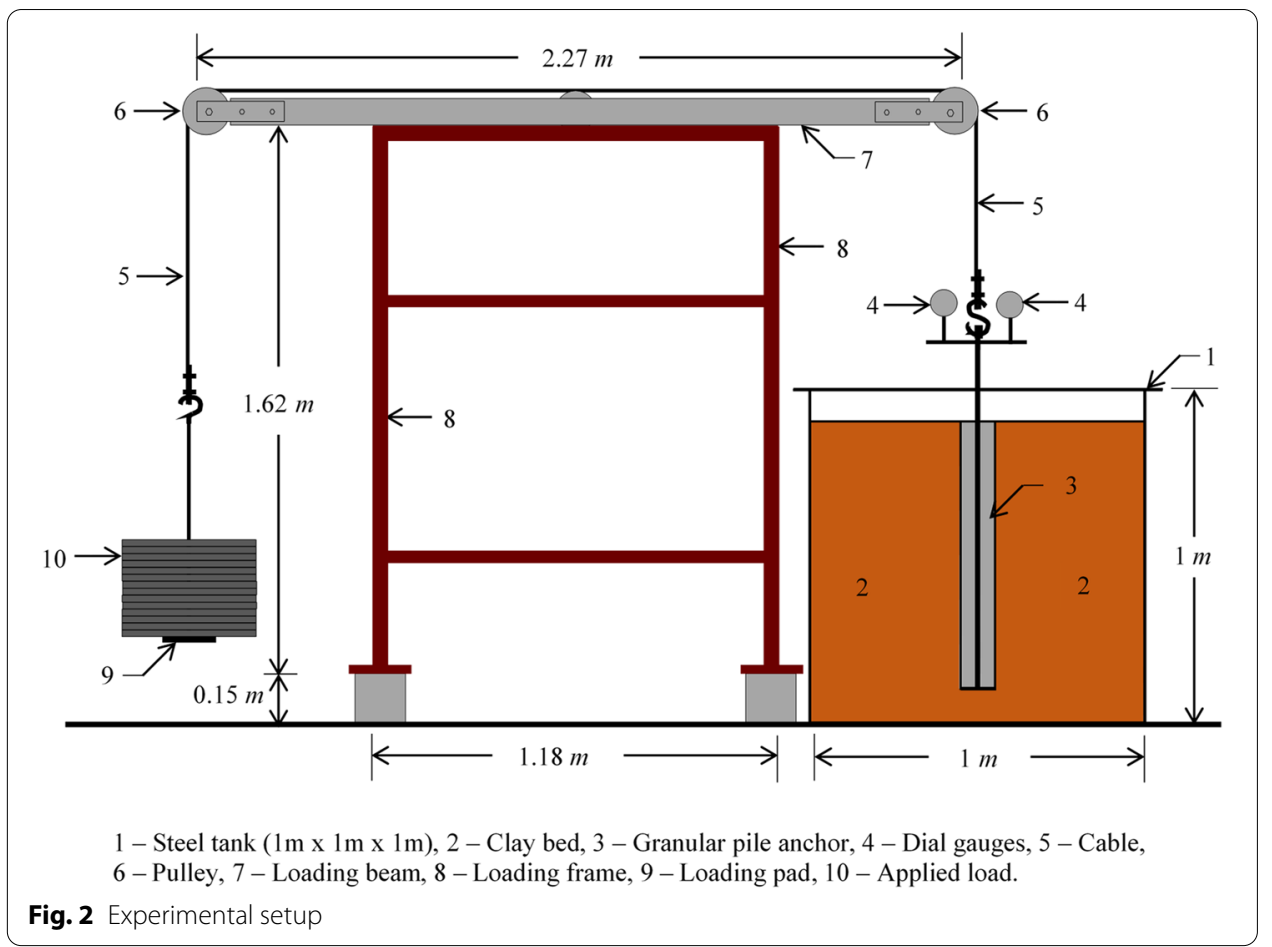

Table 1 Geotechnical properties of the clayey soil

\begin{tabular}{lc}
\hline Soil properties & Value \\
\hline Specific gravity, G & 2.53 \\
Maximum dry density, MDD $\left(\mathrm{kN} / \mathrm{m}^{3}\right)$ & 17.2 \\
Optimum moisture content, OMC (\%) & 20 \\
Unconfined compressive strength, UCS (kPa) & 110 \\
Liquid limit, LL (\%) & 53 \\
Plastic limit, PL (\%) & 26 \\
Plasticity index, PI (\%) & 27 \\
Free swell index, FSI (\%) & 32 \\
Shrinkage limit, SL (\%) & 16 \\
ISCS classification & $\mathrm{CH}$
\end{tabular}

kept on the $150 \mathrm{~mm}$ size concrete cube. Two dial gauges were used to determine the upward movement of GPA by applying pullout loading.

\section{Test materials}

\section{Clayey soil}

The clayey soil used in the experimental investigation was collected from Rahamatpur village near Piran Kaliyar, District Haridwar, Uttarakhand, India. All the tests to determine the geotechnical properties were conducted as per the respective Indian Standard (IS) code. The various geotechnical properties of the clayey soil are shown 
in Table 1 . The soil was classified as the clay of high plasticity $(\mathrm{CH})$ as per Indian Standard Classification (ISC) system.

\section{GPA materials}

A mixture of metal chips (20\%) and coarse sand (80\%) was used as the granular material. The particle size distribution curve yielded coefficient of uniformity $C_{u}=2.8$ and coefficient of curvature $C_{c}=1.3$. Mild steel bar of $12.7 \mathrm{~mm}$ diameter was used as anchor rod. It is connected to $6 \mathrm{~mm}$ thick circular mild steel anchor plate. The anchor plate was having same diameter as granular pile anchor.

\section{Test variables}

The water content of the clay bed was kept constant at the OMC (20\%) as observed in Fig. 3. The relative density $\left(D_{r}\right)$ of granular material was kept constant at $60 \%$ for the entire test GPAs. Table 2 shows the variation of diameter, $L / D$ ratio, and the number of anchor plates. A total of 14 numbers of pullout tests on single GPAs embedded in clayey soil bed were conducted. The layout of the experimental investigation is shown in Fig. 4.

\section{Preparation of clay bed and installation of GPA}

The collected clayey soil was dried and prepared in powder form. The moisture content was kept equal to OMC and was compacted to MDD. The inherent moisture content was calculated before preparation of clay bed and taken in account to maintain the OMC. Average inherent moisture content was found nearly $3.78 \%$. The clayey soil bed was prepared in the layers of $100 \mathrm{~mm}$ thickness each. The surface of the clay bed was kept covered with damped jute bags to retain the required moisture content throughout the test. The soil samples were taken at a different level of clay bed to determine the moisture content. The GPAs were installed using replacement method as suggested by Black et al. [25] after $24 \mathrm{~h}$ from the preparation of the clayey soil bed. The hole of diameter equal to GPA was drilled with the help of augur for installing GPA. After that, the anchor with an anchor plate was placed in position. Dry weight of granular material corresponding to $60 \%$ relative density was calculated for one single layer of $100 \mathrm{~mm}$. Then granular material was poured and tamped using a metal rod to the relative density of $60 \%$ in the layers of $100 \mathrm{~mm}$ each. After compaction, remaining height of hole was checked to confirm the density. This was repeated for all layers. A $50 \times 250 \mathrm{~mm}$ size rigid MS plate was fixed at the top of the anchor rod as a footing plate.

Table 2 Details of test variables

\begin{tabular}{lllc}
\hline Diameter $(\mathbf{m m})$ & LID ratio & Number of anchor plates $(n)$ & $\begin{array}{l}\text { Number of } \\
\text { tests carried } \\
\text { out }\end{array}$ \\
\hline 50 & $5,7.5,10,12.5$ & 1 & 4 \\
50 & 15 & $1,2,3$ & 3 \\
75 & $5,6.67,7.5,10$ & 1 & 4 \\
100 & $5,7.5,10$ & 1 & 3 \\
Total test & & & 14 \\
\hline
\end{tabular}



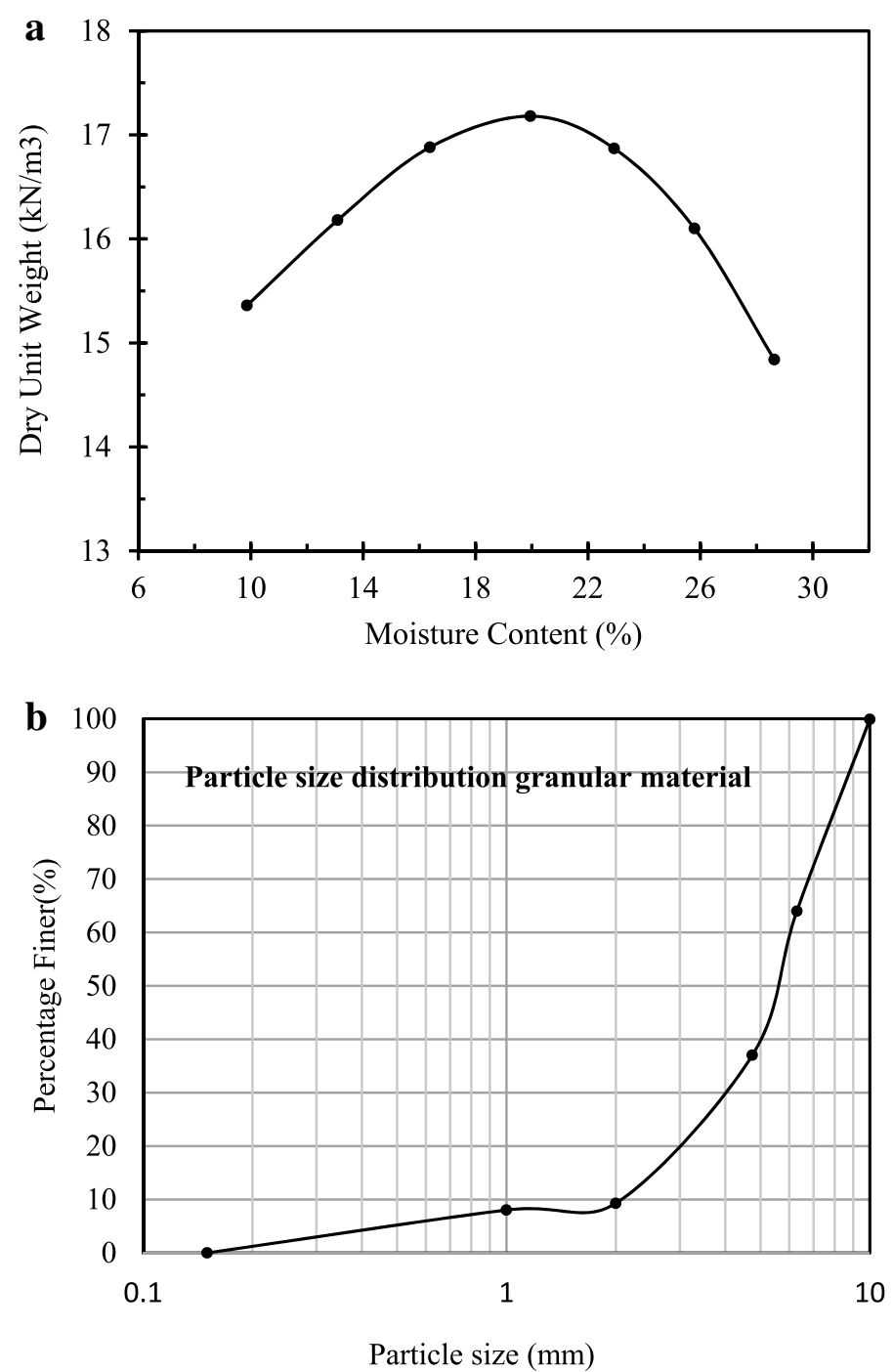

Fig. 3 a Proctor compaction curve for clayey soil. b Particle size distribution curve for GPA material

\section{Test procedure}

The pullout test on a single GPA was conducted after $24 \mathrm{~h}$ of installing the GPA. Figure 4 shows the arrangement of the pullout test for a single GPA. Two dial gauges were placed on the footing plate to determine the upward movement of GPA. The pullout load was applied on a loading pad in small increment $(20-25 \mathrm{~kg})$. The readings of dial gauges were taken when it was appeared to be constant after applying load. In the initial stage of the test, it took approximately $15 \mathrm{~min}$ time, which was reached up to $30 \mathrm{~min}$ in the final stage of the test. Additional 10 min time was given which was found to be adequate for ensuring using replacement method as suggested by Black et al. [25] final equilibrium condition considering long term behavior. The readings of dial gauges were taken and then next load increment was applied.

In case of foundations on expansive soils, upward movement greater than $10 \mathrm{~cm}$ or span/250 can cause serious distress to super-structure. IS 2911 [26] and BS 8004 [27] 
specify ultimate load corresponding to settlement of $10 \%$ pile diameter. Same is adopted here. Hence ultimate pullout load was restricted to upward movement equal to $10 \%$ pile diameter and allowable load may be taken as $50 \%$ of ultimate load from serviceability aspect (Fig. 4).

\section{Results and discussion}

The graphs were prepared between upward movement $(\mathrm{mm})$ on the $\mathrm{x}$-axis and pullout loads $(\mathrm{N})$ on the $y$-axis after conducting the pullout test to study the pullout behaviour of the GPA. The pullout capacity was determined with respect to $D / 10$ upward movement from the pullout load vs. upward movement graph. The effect of diameter, $L / D$ ratio, and multiple anchor plates on the pullout capacity was analyzed and discussed in the subsequent sections.

\section{Effect of $L / D$ ratio}

The $50 \mathrm{~mm}$ diameter single GPAs $(L / D=5,7.5,10,12.5$ and 15$), 75 \mathrm{~mm}$ and $100 \mathrm{~mm}$ diameter single GPAs $(L / D=5,7.5$ and 10$)$ were investigated to study the effect of $L / D$ ratio on the pullout capacity of the single GPA.

The pullout capacity of a $50 \mathrm{~mm}$ diameter single GPA was found as $1276 \mathrm{~N}, 1792 \mathrm{~N}$, $2175 \mathrm{~N}, 2335 \mathrm{~N}$ and $2454 \mathrm{~N}$ for $L / D$ ratio equal to $5,7.5,10,12.5$ and 15 , respectively. Figure 5 shows the pullout behaviour of a $50 \mathrm{~mm}$ diameter single GPA for different values of the $L / D$ ratio. The curves reflect the effect of the $L / D$ ratio on the pullout

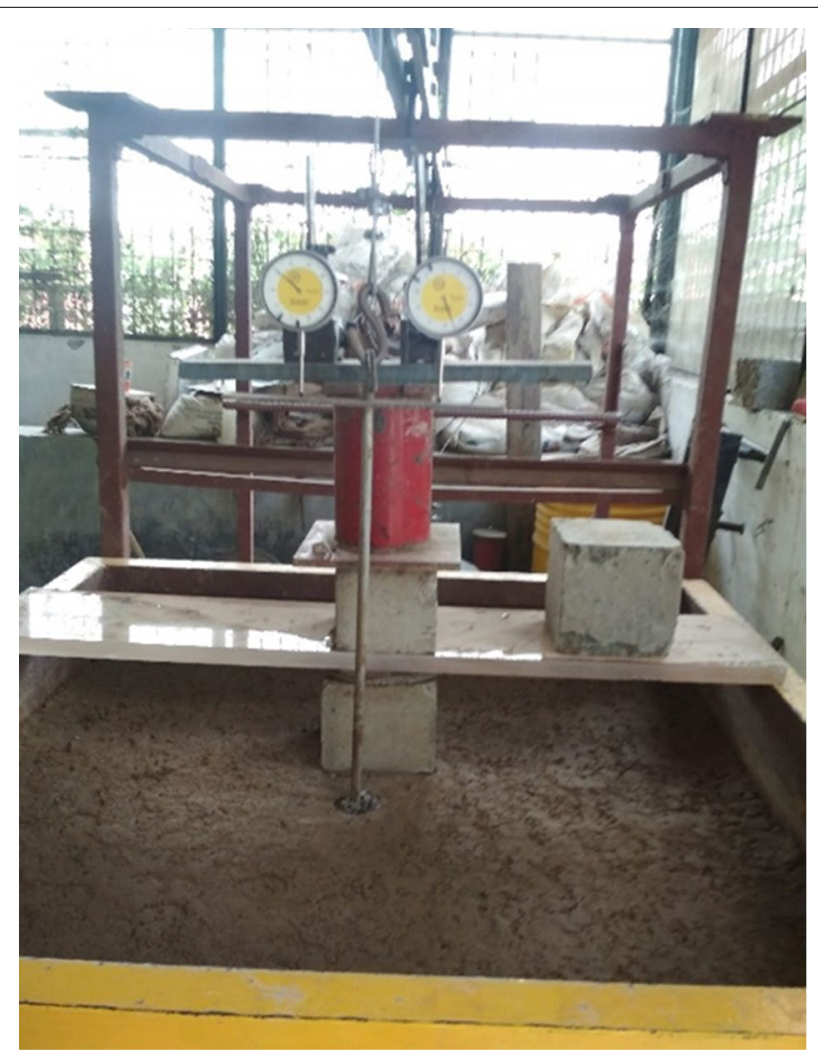

Fig. 4 The pullout test arrangement for a single GPA 


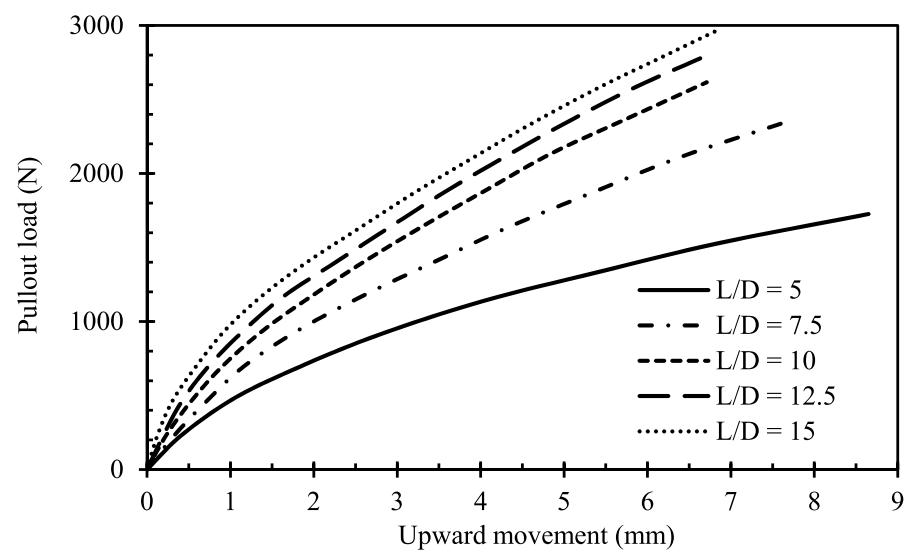

Fig. 5 Pullout behaviour of $50 \mathrm{~mm}$ diameter GPA

Table 3 Effect of the $L / D$ ratio on the pullout capacity of a $50 \mathrm{~mm}$ diameter single GPA

\begin{tabular}{lllll}
\hline LID ratio & Length $(\mathbf{m m})$ & Pullout capacity $(\mathbf{N})$ & \multicolumn{2}{l}{$\begin{array}{l}\text { Increase in the pullout capacity with } \\
\text { respect to } L / D=\mathbf{5}\end{array}$} \\
\cline { 4 - 5 } & & & & Increase (N) \\
\hline 5 & 250 & 1276 & 516 & 40 \\
7.5 & 325 & 1792 & 899 & 70 \\
10 & 500 & 2175 & 1059 & 83 \\
12.5 & 625 & 2335 & 1178 & 92 \\
15 & 750 & 2454 & & \\
\hline
\end{tabular}

capacity of a $50 \mathrm{~mm}$ diameter single GPA. All the curves show that the pullout capacity enhanced with an increase in $L / D$ ratio. As compared to $L / D=5$, the pullout capacity of a $50 \mathrm{~mm}$ diameter single GPA enhanced by $40 \%, 70 \%, 83 \%$ and $92 \%$ when $L / D$ ratio changed from 5 to $7.5,10,12.5$ and 15 respectively as reported in Table 3 . Up to the value of 10 , the effect of the $L / D$ ratio was significant.

The pullout capacity of a $75 \mathrm{~mm}$ diameter single GPA was found as $2602 \mathrm{~N}, 3603 \mathrm{~N}$ and $4395 \mathrm{~N}$ for $L / D$ ratio equal to $5,7.5$ and 10, respectively. Figure 6 shows the pullout behaviour of a $75 \mathrm{~mm}$ diameter single GPA for different values of the $L / D$ ratio. The curves reflect the effect of the $L / D$ ratio on the pullout capacity of a $75 \mathrm{~mm}$ diameter single GPA. All the curves show that the pullout capacity enhanced with an increase in the $L / D$ ratio. With respect to $L / D$ ratio equal to 5 , the pullout capacity of a $75 \mathrm{~mm}$ diameter single GPA enhanced by $38 \%$ and $69 \%$ when $L / D$ ratio changed from 5 to 7.5 and 10, respectively, as summarized in Table 4.

The pullout capacity of a $100 \mathrm{~mm}$ diameter single GPA was found as $4241 \mathrm{~N}, 5790 \mathrm{~N}$ and $7005 \mathrm{~N}$ for the $L / D$ ratio equal to $5,7.5$ and 10, respectively. Figure 7 shows the pullout behaviour of a $100 \mathrm{~mm}$ diameter single GPA for different values of the $L / D$ ratio. The curves reflect the effect of the $L / D$ ratio on the pullout capacity of a $100 \mathrm{~mm}$ diameter single GPA. All the curves show that the pullout capacity enhanced with an increase in the $L / D$ ratio. As compared to case $L / D$ ratio equal to 5 , increments in the 


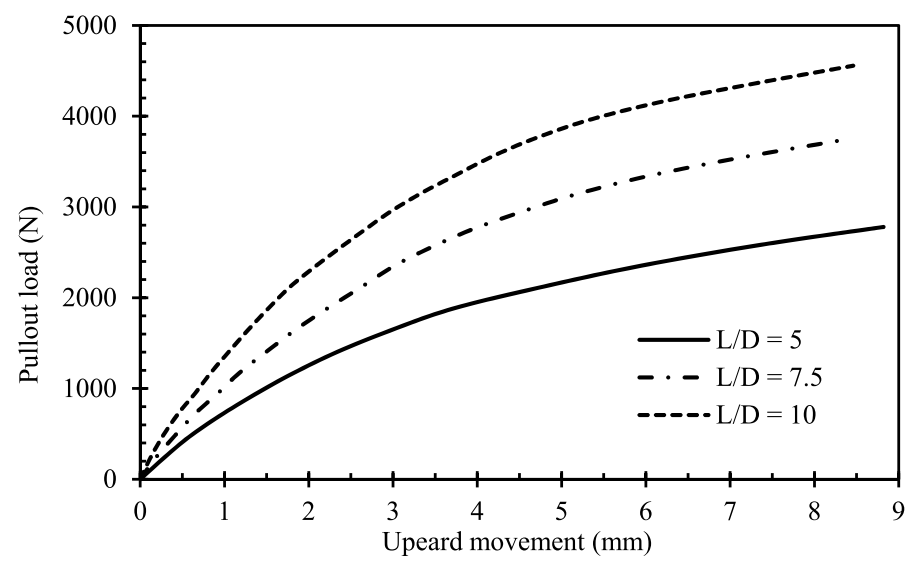

Fig. 6 Pullout behaviour of $75 \mathrm{~mm}$ diameter GPA

Table 4 Effect of the $L / D$ ratio on the pullout capacity of a $75 \mathrm{~mm}$ diameter single GPA

\begin{tabular}{lllll}
\hline LID ratio & Length $(\mathbf{m m})$ & Pullout capacity $(\mathbf{N})$ & \multicolumn{2}{l}{$\begin{array}{l}\text { Increase in the pullout capacity } \\
\text { with respect to } L / D=\mathbf{5}\end{array}$} \\
\cline { 4 - 5 } & & & & Increase (N) \\
\hline 5 & 375 & 2602 & 1001 & 38 \\
7.5 & 562 & 3603 & 1793 & 69 \\
10 & 750 & 4395 & & \\
\hline
\end{tabular}

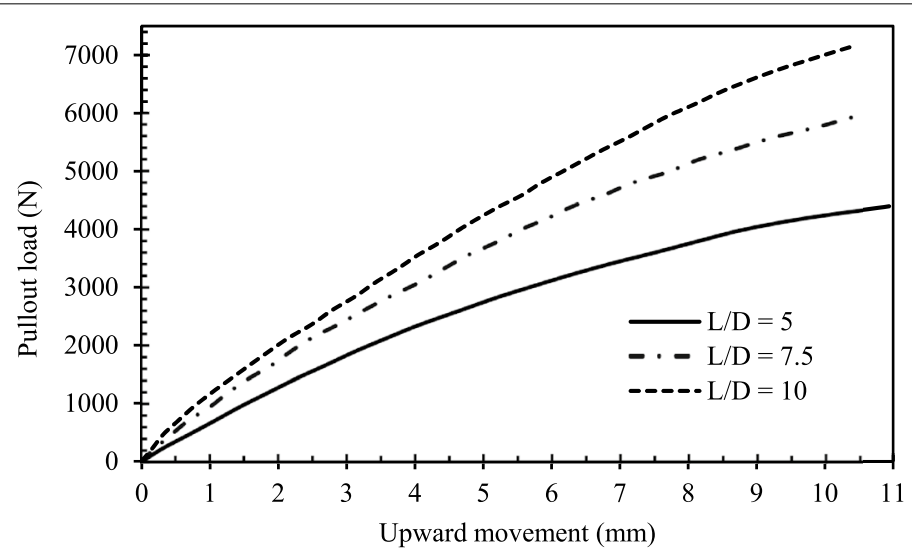

Fig. 7 Pullout behaviour of $100 \mathrm{~mm}$ diameter GPA

pullout capacity of a $100 \mathrm{~mm}$ diameter single GPA were of the order $37 \%$ and $65 \%$ when $L / D$ ratio changed from 5 to 7.5 and 10 , respectively (Table 5 ).

\section{Effect of diameter}

Tests were conducted on $50 \mathrm{~mm}, 75 \mathrm{~mm}$ and $100 \mathrm{~mm}$ diameter single GPAs to examine the effect of the diameter on the pullout capacity of the single GPA. Two aspects were considered in the variations of other parameters as constant length $(500 \mathrm{~mm})$ 
Table 5 Effect of the $L / D$ ratio on the pullout capacity of a $100 \mathrm{~mm}$ diameter single GPA

\begin{tabular}{|c|c|c|c|c|}
\hline \multirow[t]{2}{*}{ LID ratio } & \multirow[t]{2}{*}{ Length (mm) } & \multirow[t]{2}{*}{ Pullout capacity (N) } & \multicolumn{2}{|c|}{$\begin{array}{l}\text { Increase in the pullout capacity } \\
\text { with respect to } L I D=5\end{array}$} \\
\hline & & & Increase (N) & $\%$ increase \\
\hline 5 & 500 & 4241 & & \\
\hline 7.5 & 750 & 5790 & 1549 & 37 \\
\hline 10 & 1000 & 7005 & 2764 & 65 \\
\hline
\end{tabular}

and constant $L / D$ ratio $(5,7.5,10)$. Variation in pullout capacity with three diameters was compared for a particular combination of constant length or constant $L / D$ ratio.

\section{Constant length $500 \mathrm{~mm}$}

The pullout capacity of a single GPA with a constant length as $500 \mathrm{~mm}$ was found as $2175 \mathrm{~N}, 3328 \mathrm{~N}$ and $4241 \mathrm{~N}$ for diameter equal to $50 \mathrm{~mm}, 75 \mathrm{~mm}$ and $100 \mathrm{~mm}$, respectively. Figure 8 shows the pullout behaviour of a $500 \mathrm{~mm}$ long single GPA for different values of the diameter. All the curves show that the pullout capacity improved with an increase in the diameter of the single GPA. With respect to $50 \mathrm{~mm}$ diameter GPA, the pullout capacity was enhanced by $53 \%$ and $95 \%$ when diameter was changed from 50 to $75 \mathrm{~mm}$ and $100 \mathrm{~mm}$, respectively. Pullout capacities and increments are reported in Table 6.

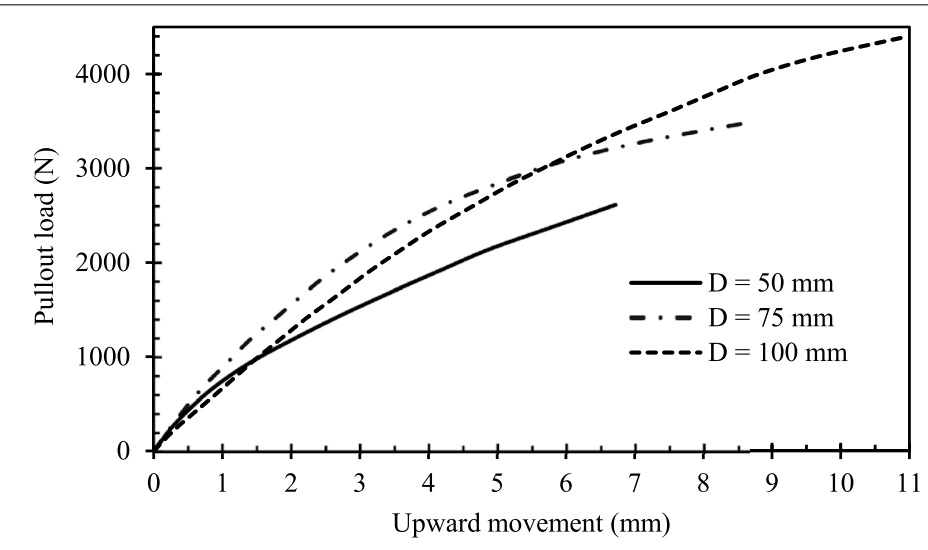

Fig. 8 Pullout behaviour of constant length GPA $(L=500 \mathrm{~mm})$

Table 6 Effect of the diameter on the pullout capacity of a $500 \mathrm{~mm}$ long single GPA

\begin{tabular}{lllll}
\hline Diameter $(\mathbf{m m})$ & LID ratio & Pullout capacity $(\mathbf{N})$ & $\begin{array}{l}\text { Increase in the pullout capacity } \\
\text { with respect to } D=\mathbf{5 0 ~} \mathbf{~ m m}\end{array}$ \\
\hline 50 & & Increase (N) & \% increase \\
75 & 10 & 2175 & & 53 \\
100 & 6.67 & 3328 & 1153 & 95 \\
\hline
\end{tabular}




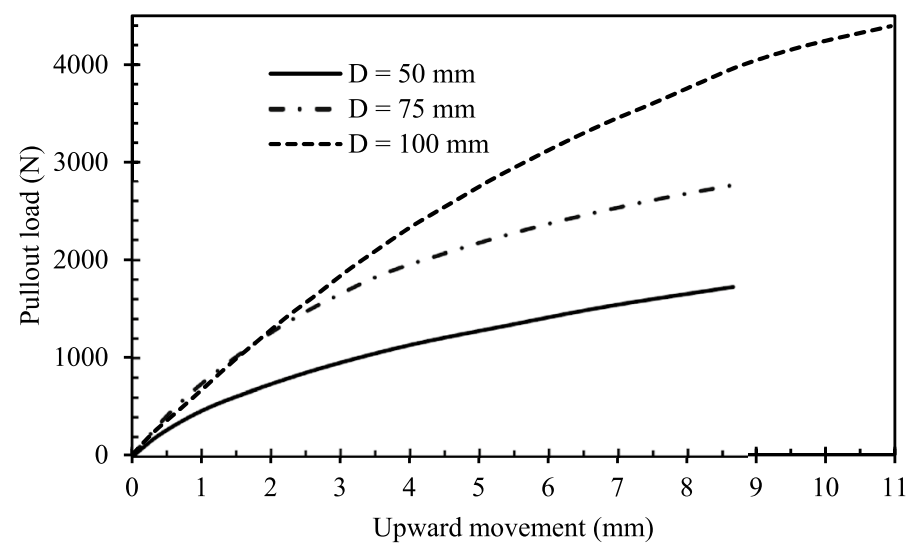

Fig. 9 Pullout behaviour of GPA with $L / D=5$

Table 7 Effect of the diameter on the pullout capacity for a single GPA with $L / D=5$

\begin{tabular}{llllc}
\hline Diameter $(\mathbf{m m})$ & Length $(\mathbf{m m})$ & $\begin{array}{l}\text { Pullout capacity } \\
(\mathbf{N})\end{array}$ & \multicolumn{2}{l}{$\begin{array}{l}\text { Increase in the pullout capacity } \\
\text { with respect to } D=\mathbf{5 0 ~} \mathbf{~ m m}\end{array}$} \\
\cline { 4 - 4 } & & & & Increase (N) \\
\hline 50 & 250 & 1276 & 1326 & 104 \\
75 & 375 & 2602 & 2965 & 232 \\
\hline 00 & 500 & 4241 & & \\
\hline
\end{tabular}

\section{Constant $L / D$ ratio 5}

The pullout capacity of a single GPA with a constant $L / D$ ratio equal to 5 was found as $1276 \mathrm{~N}, 2602 \mathrm{~N}$ and $4241 \mathrm{~N}$ for diameter equal to $50 \mathrm{~mm}, 75 \mathrm{~mm}$ and $100 \mathrm{~mm}$, respectively. Figure 9 shows the pullout behaviour of a single GPA with a constant $L / D$ ratio equal to 5 for different values of the diameter. All the curves show that the pullout capacity enhanced with an increase in the diameter of the GPA. It was found that the pullout capacity of a single GPA with a constant $L / D$ ratio equal to 5 enhanced $104 \%$ and $232 \%$ when the diameter changed from 50 to $75 \mathrm{~mm}$ and $100 \mathrm{~mm}$, respectively with respect to $50 \mathrm{~mm}$ diameter single GPA, as shown in Table 7.

\section{Constant $L / D$ ratio 7.5}

The pullout capacity of a single GPA with a constant $L / D$ ratio equal to 7.5 was found as $1792 \mathrm{~N}, 3603 \mathrm{~N}$ and $5790 \mathrm{~N}$ for diameter equal to $50 \mathrm{~mm}, 75 \mathrm{~mm}$ and $100 \mathrm{~mm}$, respectively. Figure 10 shows the pullout behaviour of a single GPA with a constant $L / D$ ratio equal to 7.5 for different values of the diameter. All the curves show that the pullout capacity enhanced with an increase in the diameter of the GPA. It was found that the pullout capacity of a single GPA with $L / D$ ratio equal to 7.5 enhanced $101 \%$ and $223 \%$ when diameter changed from 50 to $75 \mathrm{~mm}$ and $100 \mathrm{~mm}$, respectively with respect to $50 \mathrm{~mm}$ diameter GPA as shown in Table 8 . 


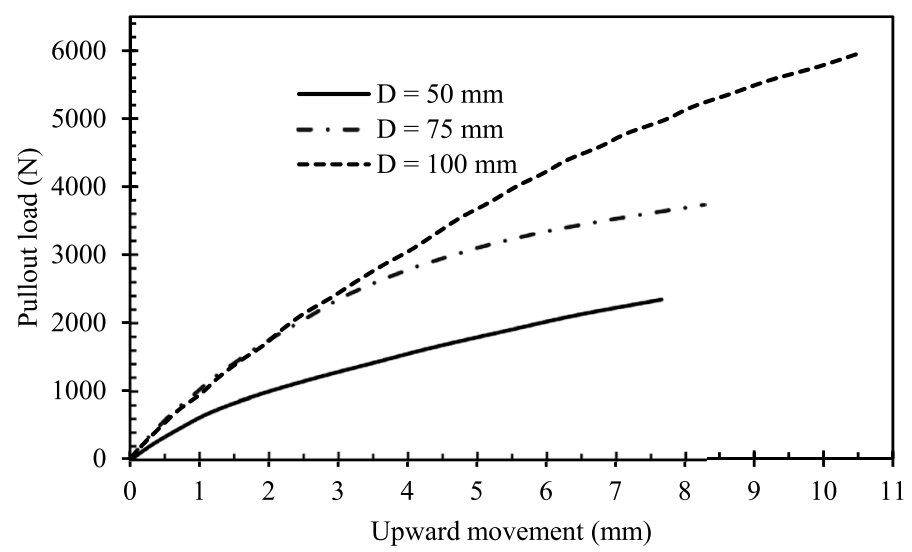

Fig. 10 Pullout behaviour of GPA with $L / D=7.5$

Table 8 Effect of the diameter on the pullout capacity for a GPA with $L / D=7.5$

\begin{tabular}{lllll}
\hline Diameter $(\mathbf{m m})$ & Length $(\mathbf{m m})$ & $\begin{array}{l}\text { Pullout capacity } \\
\text { (N) }\end{array}$ & \multicolumn{2}{l}{$\begin{array}{l}\text { Increase in the pullout capacity } \\
\text { with respect to } D=\mathbf{5 0 ~} \mathbf{~ m m}\end{array}$} \\
\cline { 4 - 4 } & & 1792 & \% increase \\
\hline 50 & 375 & 3603 & 1811 & 101 \\
75 & 562 & 5790 & 3998 & 223 \\
\hline 100 & 750 & &
\end{tabular}

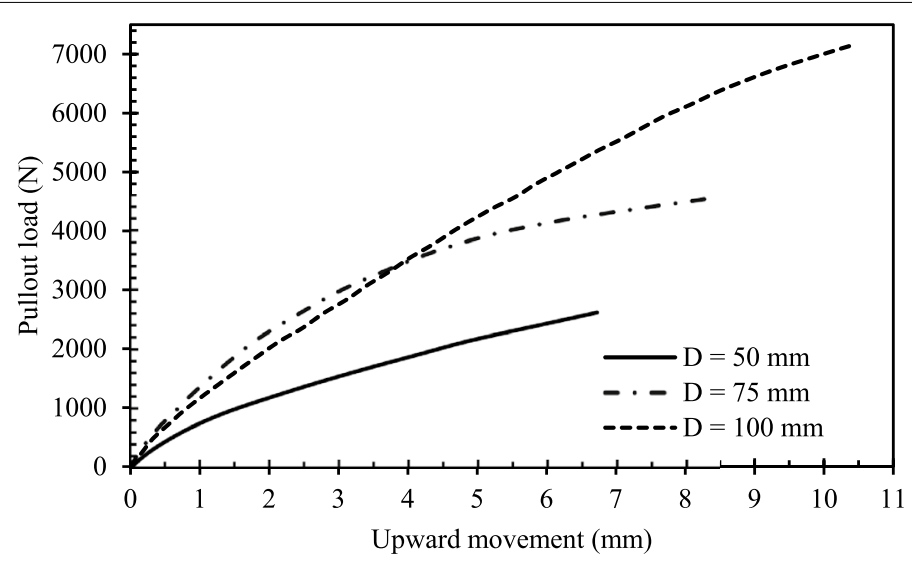

Fig. 11 Pullout behaviour of GPA with $L / D=10$

\section{Constant $L / D$ ratio 10}

The pullout capacity of a single GPA with a constant $L / D$ ratio equal to 10 was found as $2175 \mathrm{~N}, 4395 \mathrm{~N}$ and $7005 \mathrm{~N}$ for diameter equal to $50 \mathrm{~mm}, 75 \mathrm{~mm}$ and $100 \mathrm{~mm}$, respectively. Figure 11 shows the pullout behaviour of a single GPA with a constant $L / D$ ratio equal to 10 for different values of diameter. All the curves show that the pullout capacity enhanced with an increase in the diameter of a single GPA. It was found that the pullout capacity of a single GPA with $L / D$ ratio equal to 10 enhanced 
$102 \%$ and $222 \%$ when diameter changed from 50 to $75 \mathrm{~mm}$ and $100 \mathrm{~mm}$, respectively with respect to $50 \mathrm{~mm}$ diameter single GPA, as shown in Table 9.

\section{Effect of providing multiple anchor plates}

The $50 \mathrm{~mm}$ diameter and $750 \mathrm{~mm}$ long single GPAs with the varying number of anchor plates $(n)$ as 1,2 and 3 were investigated to examine the effect of providing multiple anchor plates on the pullout capacity. The pullout capacities of single GPA were found as $2454 \mathrm{~N}, 2463 \mathrm{~N}$ and $2434 \mathrm{~N}$ for varying number of anchor plates as 1, 2 and 3, respectively. No significant effect was found for providing multiple anchor plates, as evident from Table 10.

A summary of the results is presented in Table 11. The pullout capacity of a single GPA for different diameter and $L / D$ ratio are given. A comparison is made by showing the percentage increase in the pullout capacity with respect to a single GPA having $50 \mathrm{~mm}$ diameter and $L / D$ ratio equal to 5 . The pullout capacity of a $50 \mathrm{~mm}$ diameter single GPA enhanced $70 \%$ and $232 \%$ when the $L / D$ ratio changed from 5 to 10 and diameter changed from 50 to $100 \mathrm{~mm}$, respectively. The pullout capacity of a $50 \mathrm{~mm}$ diameter single GPA enhanced $449 \%$ when both the $L / D$ ratio and diameter changed from 5 to 10 and $50 \mathrm{~mm}$

Table 9 Effect of the diameter on the pullout capacity for a single GPA with $L / D=10$

\begin{tabular}{llllc}
\hline Diameter $(\mathbf{m m})$ & Length $(\mathbf{m m})$ & $\begin{array}{l}\text { Pullout capacity } \\
\text { (N) }\end{array}$ & & \multicolumn{2}{l}{$\begin{array}{l}\text { Increase in the pullout capacity } \\
\text { with respect to } D=\mathbf{5 0 ~} \mathbf{~ m m}\end{array}$} \\
\cline { 4 - 5 } & & 2175 & Increase (N) & \% increase \\
\hline 50 & 500 & 4395 & 2220 & 102 \\
75 & 750 & 7005 & 4830 & 222 \\
100 & 1000 & & & \\
\hline
\end{tabular}

Table 10 Effect of number of anchor plates on the pullout capacity for a $50 \mathrm{~mm}$ diameter and $750 \mathrm{~mm}$ long single GPA

\begin{tabular}{|c|c|c|c|c|}
\hline \multirow[t]{2}{*}{ Length (mm) } & \multirow[t]{2}{*}{$\begin{array}{l}\text { Number of anchor } \\
\text { plates }\end{array}$} & \multirow[t]{2}{*}{ Pullout capacity (N) } & \multicolumn{2}{|c|}{$\begin{array}{l}\text { Increase in the pullout capacity } \\
\text { with respect to the single anchor } \\
\text { plate }\end{array}$} \\
\hline & & & Increase (N) & $\%$ increase \\
\hline \multirow[t]{3}{*}{750} & 01 & 2454 & & \\
\hline & 02 & 2463 & 9 & 0.4 \\
\hline & 03 & 2434 & -20 & -0.8 \\
\hline
\end{tabular}

Table 11 Comparison of the pullout capacity of a single GPA for different cases

\begin{tabular}{|c|c|c|c|c|c|c|c|c|c|c|c|c|}
\hline \multirow[t]{3}{*}{ Diameter (mm) } & \multicolumn{6}{|c|}{ Pullout capacity (N) } & \multicolumn{6}{|c|}{$\begin{array}{l}\% \text { Increase in the pullout capacity } \\
\text { with respect to GPA having } \\
D=50 \mathrm{~mm} \text { and } L / D=5\end{array}$} \\
\hline & \multicolumn{6}{|c|}{ LID ratio } & \multicolumn{6}{|c|}{ L/D ratio } \\
\hline & 5 & 6.67 & 7.5 & 10 & 12.5 & 15 & 5 & 6.67 & 7.5 & 10 & 12 & 15 \\
\hline 50 & 1276 & - & 1792 & 2175 & 2335 & 2454 & 0 & - & 40 & 70 & 83 & 92 \\
\hline 75 & 2602 & 3328 & 3603 & 4395 & - & - & 104 & 161 & 182 & 244 & - & - \\
\hline 100 & 4241 & - & 5790 & 7005 & - & - & 232 & - & 354 & 449 & - & - \\
\hline
\end{tabular}




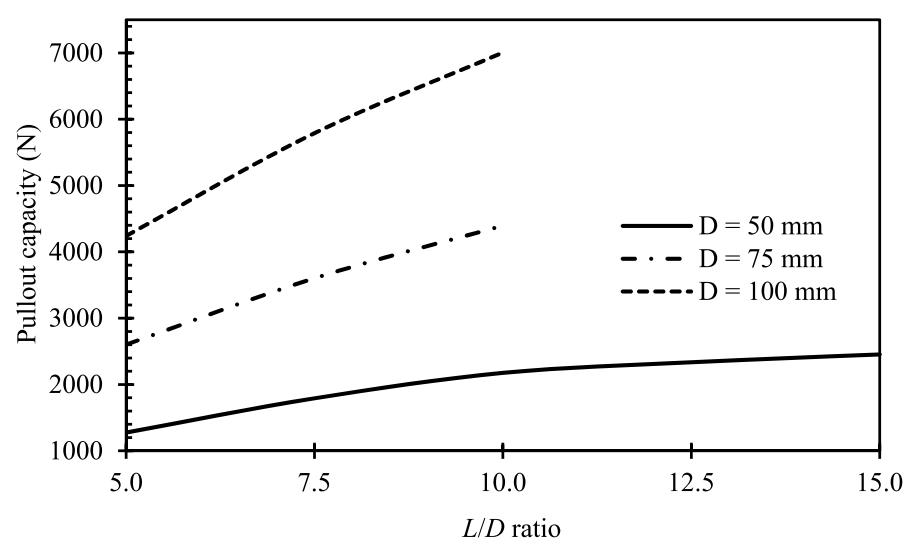

Fig. 12 Variation in pullout capacity with $L / D$ ratio

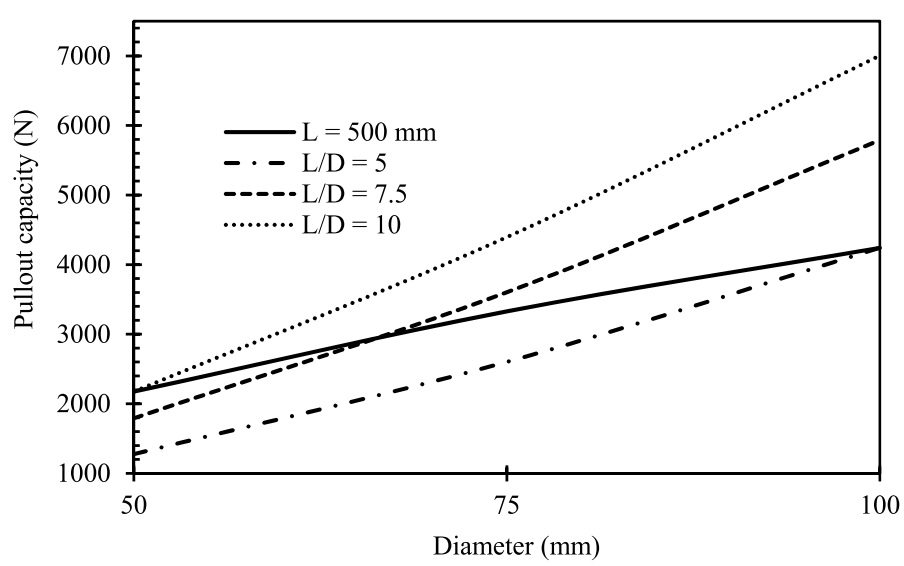

Fig. 13 Variation in pullout capacity with diameter

to $100 \mathrm{~mm}$, respectively. Figure 12 shows the variation of the pullout capacity with the $L / D$ ratio for different values of the diameter of a single GPA.

Figure 13 shows the variation of the pullout capacity of a single GPA with varying diameter for different cases as constant length $(500 \mathrm{~mm})$ and constant $L / D$ ratio $(5$, 7.5 , and 10). The variation of the pullout capacity of a single GPA with a constant $L / D$ ratio was steeper than a single GPA with a constant length since the surface area of GPA with constant $L / D$ ratio increased more than GPA with constant length when diameter increased.

The normalized pullout capacity $\bar{P}=P_{u} /\left(S_{u} \pi D L\right)$ was considered to further elaborate the results obtained. The value of the normalized pullout capacity for different cases is shown in Table 12. The variation of the normalized pullout capacity with varying $L / D$ ratio for different diameter of GPA is shown in Fig. 14. All the curves show that the normalized pullout capacity decreased with an increase in the $L / D$ ratio of GPA as the mobilized shear resistance was less for GPA having a higher $L / D$ ratio for the same upward movement $(D / 10)$. The value of normalized pullout capacity for a constant $L / D$ ratio is higher for $50 \mathrm{~mm}$ diameter GPA than $75 \mathrm{~mm}$ and $100 \mathrm{~mm}$ diameter GPA as the mobilized shear resistance was higher in case of a $50 \mathrm{~mm}$ diameter 
Table 12 Variation of the non-dimensional pullout capacity $(\bar{P})$

\begin{tabular}{|c|c|c|c|c|c|c|}
\hline \multirow[t]{2}{*}{ Diameter (mm) } & \multicolumn{6}{|c|}{ Value of the non-dimensional pullout capacity $(\bar{P})$} \\
\hline & $L / D=\mathbf{5}$ & 6.67 & 7.5 & 10 & 12.5 & 15 \\
\hline 50 & 0.591 & - & 0.553 & 0.504 & 0.432 & 0.379 \\
\hline 75 & 0.535 & 0.514 & 0.495 & 0.452 & - & - \\
\hline 100 & 0.491 & - & 0.447 & 0.405 & - & - \\
\hline
\end{tabular}

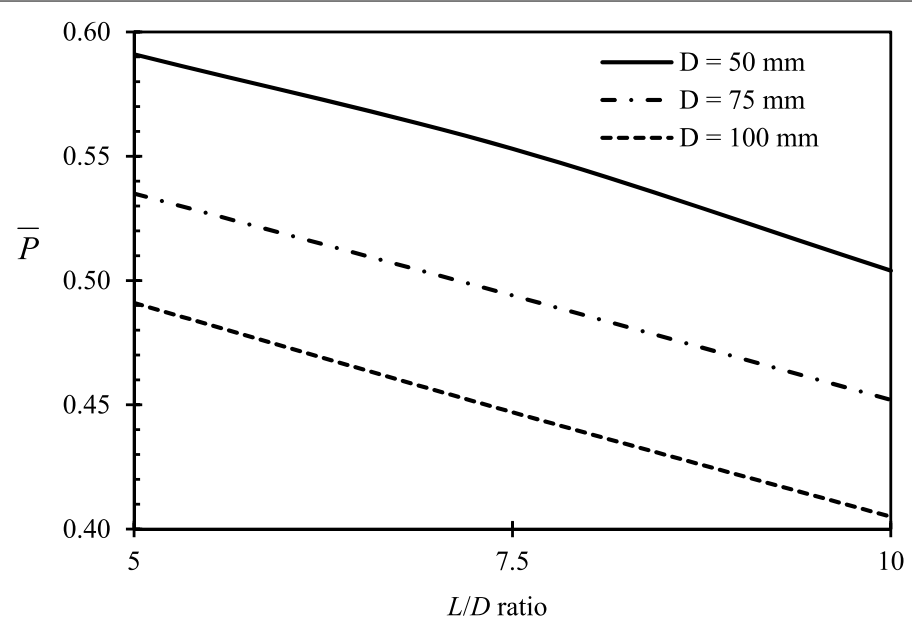

Fig. 14 Variation in non-dimensional pullout capacity with $L / D$ ratio

GPA than $75 \mathrm{~mm}$ and $100 \mathrm{~mm}$ diameter GPA. From the statistical analysis of normalized pullout capacity $\bar{P}$ for different cases, following relationship was proposed to predict $\bar{P}$.

$$
\bar{P}=0.689-0.002 D-0.01707(L / D-5)
$$

However, it is to be noted that the proposed relationship can be used only up to $L / D$ ratio 10 . Beyond this limit, relationship is no longer linear. The effect of the $L / D$ ratio is marginal for further increase in the $L / D$ ratio.

\section{Comparison with Sharma and Sharma [21]}

Sharma and Sharma [21] have conducted laboratory experiments to study the pullout behaviour of GPA in the clayey soil bed. A cast-iron tank of $0.3 \times 0.3 \times 0.6 \mathrm{~m}$ size was used for investigation. The clay bed was prepared at its OMC and MDD for all pullout tests. The geotechnical properties of the clayey soil used in the present study were almost similar (Table 13) to those used by Sharma and Sharma [21]. The pullout behaviour of a single GPA with the different diameters with $L / D=5$ of the present study was compared with the $60 \mathrm{~mm}$ diameter single GPA for the same $L / D$ ratio as presented by Sharma and Sharma [21] as shown in Fig. 15. The results of the present study were in good agreement with Sharma and Sharma [21]. 
Table 13 Comparison of geotechnical properties of the clayey soil used in the present study and Sharma and Sharma [21]

\begin{tabular}{lll}
\hline Soil properties & Value & \\
\cline { 2 - 3 } & Present study & $\begin{array}{l}\text { Sharma and } \\
\text { Sharma } \\
\text { (2019) }\end{array}$ \\
\hline Specific gravity, G & & 2.65 \\
Maximum dry density, MDD $\left(\mathrm{kN} / \mathrm{m}^{3}\right)$ & 2.53 & 16.4 \\
Optimum moisture content, OMC (\%) & 17.2 & 20 \\
Liquid limit, LL (\%) & 20 & 53.20 \\
Plastic limit, PL (\%) & 53 & 27.80 \\
Plasticity index, Pl (\%) & 26 & 25.40 \\
DFS (\%) & 27 & 49.90 \\
ISCS classification & 32 & $\mathrm{CH}$ \\
\hline
\end{tabular}

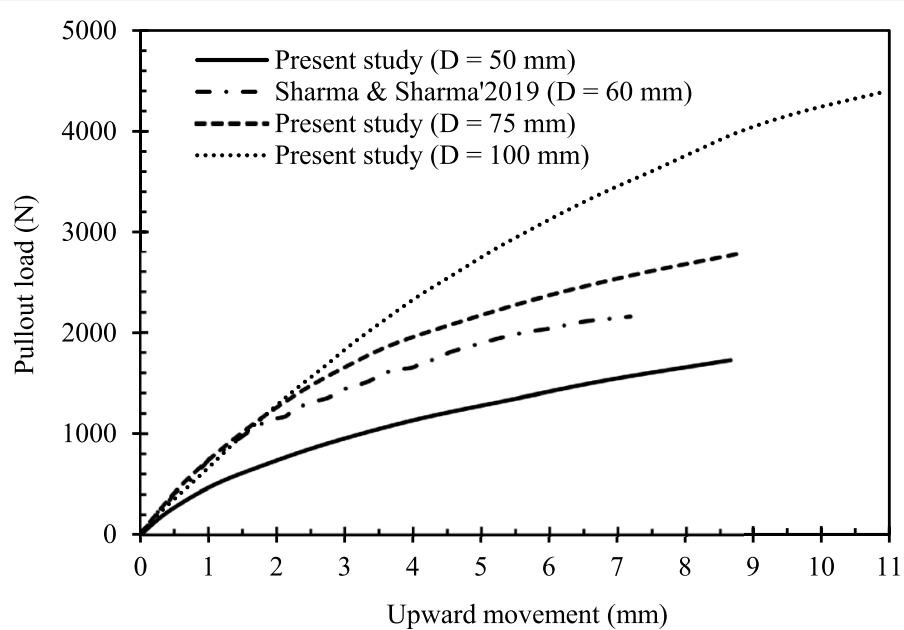

Fig. 15 Comparison of the present study with Sharma and Sharma [21] for $L / D=5$

\section{Conclusions}

An experimental investigation was carried out to study the pullout response of a single GPA embedded in the clayey soil bed. The diameter of the GPA was varied as $50 \mathrm{~mm}, 75 \mathrm{~mm}$, and $100 \mathrm{~mm}$, and $L / D$ ratio was varied as $5-15$. The number of anchor plates was varied as 1,2 , and 3 . The investigation studied the pullout load vs. upward movement behaviour of a single GPA. The moisture content of the clay bed was kept constant at $20 \%$ (OMC). The effect of variation in diameter, $L / D$ ratio, and the number of anchor plates on the pullout capacity of a single GPA was examined. The main conclusions drawn from the present study are as follows:

1. The pullout capacity of a single GPA enhanced with an increase in diameter and $L / D$ ratio since the surface area of GPA enhanced with an increase in diameter and $L / D$ ratio. 
2. The pullout capacity of a $50 \mathrm{~mm}$ diameter single GPA enhanced $70 \%$ and $232 \%$ when the $L / D$ ratio changed from 5 to 10 , and diameter changed from 50 to $100 \mathrm{~mm}$, respectively.

3. The pullout capacity of a $50 \mathrm{~mm}$ diameter single GPA enhanced $449 \%$ when both the $L / D$ ratio and diameter changed from 5 to 10 and $50 \mathrm{~mm}$ to $100 \mathrm{~mm}$, respectively.

4. Up to the value of 10 , the effect of the $L / D$ ratio was appreciable for $50 \mathrm{~mm}$ diameter single GPA.

5. The variation of the pullout capacity of GPA with a constant $L / D$ ratio was steeper than GPA with a constant length since the surface area of GPA with constant $L / D$ ratio enhanced more than GPA with constant length when diameter increased.

6. No significant effect of providing multiple anchor plates on the pullout capacity of a single GPA was found.

7. The normalized pullout capacity $(\bar{P})$ decreased with an increase in the $L / D$ ratio of GPA since the mobilized shear resistance was less for GPA having a higher $L / D$ ratio for the same upward movement $(D / 10)$. From the statistical analysis of normalized pullout capacity $\bar{P}$ for different cases, a relationship was proposed to predict $\bar{P}$.

8. The normalized pullout capacity for a constant $L / D$ ratio was higher for $50 \mathrm{~mm}$ diameter GPA than $75 \mathrm{~mm}$ and $100 \mathrm{~mm}$ diameter GPA as the mobilized shear resistance was higher in case of a $50 \mathrm{~mm}$ diameter GPA than $75 \mathrm{~mm}$ and $100 \mathrm{~mm}$ diameter GPA.

\begin{abstract}
Abbreviations
$C_{c}$ : Coefficient of curvature; $C_{u}$ : Coefficient of uniformity; $D_{f}$ : Diameter of footing; $D_{\text {gpa }}$ : The diameter of granular pile anchor; $D_{r}$ : Relative density; $K_{s}$ : Coefficient of lateral swelling pressure; $L_{g p a}$ : Length of granular pile anchor; $P_{R}$ : Resistance to uplift; $p_{s}$ : Swelling pressure; $P_{u}$ : Uplift force, Pullout capacity; $\bar{P}$ : Normalized pullout capacity; $S_{u}:$ Undrained shear strength; $W_{g p a}:$ Self-weight of granular pile anchor.
\end{abstract}

\title{
Acknowledgements
}

The first author wants to thanks the Irrigation and Water Resources Department Uttar Pradesh for kindly sponsoring him to undertake the present study and Er. Bhartendu Gaur, S.E., for his valuable support.

\section{Authors' contributions}

HRV performed experimental study and presented study in graphical form. VAS analyzed data in non-dimensional for to propose a new equation for normalized pullout capacity. HRV prepared the manuscript and VAS review the same before submission. Both the authors read and approved the final manuscript.

\section{Declarations}

Competing interests

The authors declare that they have no competing interests.

Received: 28 October 2020 Accepted: 11 July 2021

Published online: 01 December 2021

\section{References}

1. Kumar BRP, Rao NR (2000) Increasing pull-out capacity of granular pile anchors in expansive soils using base geosynthetics. Can Geotech J 37(4):870-881

2. Ranjan G, Kumar P (2000) Behaviour of granular piles under compressive and tensile loads. Geotech Eng J of SEAGS 31(3):209-214

3. Phanikumar BR, Sharma RS, Rao AS, Madhav MR (2004) Granular pile anchor foundation (GPAF) system for improving the engineering behavior of expansive clay beds. Geotech Test J 27(3):279-287

4. Rao AS, Phanikumar BR, Babu RD, Suresh K (2007) Pullout behavior of granular pile-anchors in expansive clay beds in situ. J Geotech Geoenvironmental Eng 133(5):531-538 
5. Vidyaranya B, Madhav MR, Kumar M (2009) Elasto-plastic analysis for displacements of granular pile anchors (GPA) in non-homogenous ground. Lowl Technol Int 11(2):14-20

6. Ismail M, Shahin M (2012) Numerical modeling of granular pile-anchor foundations (GPAF) in reactive soils. Int J Geotech Eng 6(2):149-155

7. Sivakumar V, O'Kelly BC, Madhav MR, Moorhead C, Rankin B (2012) Granular anchors under vertical loading-axial pull. Can Geotech J 50(2):123-132

8. Krishna PH, Murty VR, Vakula J (2013) A field study on Heave reduction of Flooring panels resting on expansive soils using granular anchor piles and cushions. Int J Eng Sci ASCE 2(3):111

9. Krishna PH, Murty VR (2013) Pull-out capacity of granular anchor piles in expansive soils. IOSR J Mech Civil Eng 5(1):24

10. Ibrahim SF, Aljornay AN, Aladly Al (2014) Heave behaviour of granular pile anchor-foundation (GPA-foundation) system in expansive soil. J Civ Eng Urbanism 4(3):213-222

11. O'Kelly BC, Brinkgreve RBJ, Sivakumar V (2014) Pullout resistance of granular anchors in clay for undrained condition. Soils Found 54(6):1145-1158

12. Reddy OE, Madhav MR, Reddy ES (2015) Ultimate pullout capacity of the granular pile anchors by laboratory model tests. Indian J Geosynth Ground Improv 4(1):25-33

13. Abhishek SV, Rajyalakshmi K, Madhav MR (2016) Engineering of ground with granular piles: a critical review. Int J Geotech Eng 10(4):337-357

14. Johnson N, Sandeep MN (2016) Ground improvement using granular pile anchor foundation. Procedia Technol 24:263-270

15. Kranthikumar A, Sawant VA, Kumar P, Shukla SK (2016) Numerical and experimental investigations of granular anchor piles in loose sandy soil subjected to uplift loading. Int J Geomech 17(2):04016059

16. Muthukumar M, Shukla SK (2016) Swelling behaviour of expansive clay beds reinforced with encased granular pile anchors. Int J Geotech Eng 12(2):109-117

17. Phanikumar BR (2016) Influence of geogrid reinforcement on pullout response of granular pile-anchors (GPAs) in expansive soils. Indian Geotech J 46(4):437-444

18. Muthukumar M, Shukla SK (2017) Comparative study on the behaviour of granular pile anchors and helical pile anchors in expansive soils subjected to swelling. Int J Geotech Eng 1-6:49

19. Sharma RK (2018) A numerical study of granular pile anchors subjected to uplift forces in expansive soils using PLAXIS 3D. Indian Geotech J 1-10:304

20. Phanikumar BR, Muthukumar M (2019) Influence of wetting-drying cycles on swell-shrink behaviour of GPA-reinforced expansive clay beds. Geomech Geoengin 1-14:172

21. Sharma A, Sharma RK (2019) An experimental study on uplift behaviour of granular anchor pile in stabilized expansive soil. Int J Geotech Eng 1-14:1

22. Singh J, Mital A, Arora VK (2019) Load displacement behaviour of granular anchor pile (GAP) and group piles under oblique pullout loads. Indian Geotech J 49(1):100-107

23. Phanikumar BR, Raghuram ASS, Sriramarao A (2020) Improving expansive clay beds with granular pile anchors (GPAs) and geogrid-encased GPAs. Proc Inst Civil Eng Ground Improv 173(4):237-248. https://doi.org/10.1680/jgrim. 18.0008

24. Phanikumar BR, Etukuri RR (2021) Effect of granular piles with geotextile encasement on strength tests of expansive clays. Proc Inst Civil Eng Ground Improv. https://doi.org/10.1680/jgrim.18.00052

25. Black JA, Sivalumar V, Bell A (2011) The settlement performance of stone column foundations. Geotechnique 61(11):909-922

26. IS 2911 (Part 4) : 1984, Code of practice for design and construction of pile foundations., Bureau of IndianStandards.

27. BS 8004:1986, 'Code of Practice for Foundations', British Standard.

\section{Publisher's Note}

Springer Nature remains neutral with regard to jurisdictional claims in published maps and institutional affiliations.

\section{Submit your manuscript to a SpringerOpen ${ }^{\circ}$ journal and benefit from:}

- Convenient online submission

- Rigorous peer review

- Open access: articles freely available online

- High visibility within the field

Retaining the copyright to your article

Submit your next manuscript at $\gg$ springeropen.com 